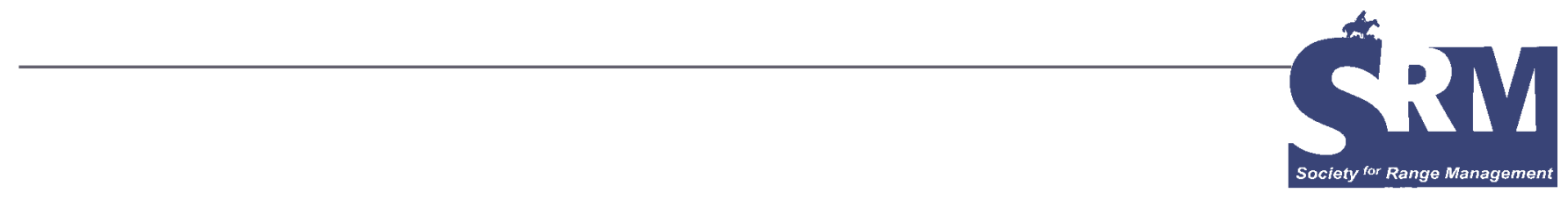

\title{
Speaking With People in Our Profession
}

\section{An interview with Dr Elisabeth Huber-Sannwald}

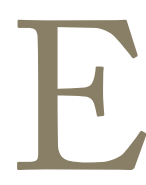

lisabeth Huber-Sannwald is an Associate Professor in the Division of Environmental Sciences at the Institute for Scientific and Technological Research in San Luis Potosi, Mexico (www.ipicyt.edu.mx/ Englishnew/AboutIPICYT/). Elisabeth completed her PhD in Rangeland Ecology at Utah State University in 1996. She has served in international research positions in Argentina and Germany before settling in Mexico in 2001. She has authored a number of important publications on biodiversity and management of arid grasslands, and has worked with other leading scientists in this research field over the past 10 years. She had a few minutes while hosting a conference on sustainability of arid grasslands in central Mexico this past August to respond to a few questions about her interests and activities.

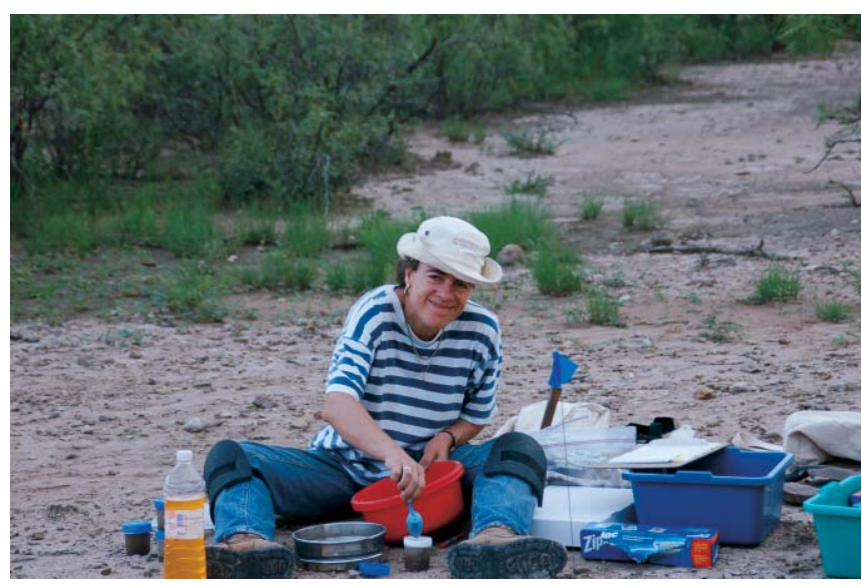

Elisabeth Huber-Sannwald working at a field site in the Chihuahuan Desert on her studies of nitrogen dynamics in a halophytic grassland that has been heavily invaded by mesquite shrubs.

\section{Working to Create Options}

Question: You are a native Austrian who has worked in grassland environments on at least 3 continents. What attracted you to these landscapes?

Answer: It wasn't really the landscapes that attracted me, but the research programs. In Austria I was involved in botanical studies, learning vegetation systematics, and then vegetation inventories, mapping plant associations and communities ranging from endangered riparian forests in valley bottoms to highly diverse grasslands in the alpine region, and I became addicted to these fields in botany. And then I started to see patterns in nature, and that it wasn't just an issue of inventory but of understanding the underlying mechanisms of these patterns and how they could be managed. However, there were no programs at that time in Austria for learning about land management. Professor Walter Larcher at the University of Innsbruck told me I need to study abroad to learn experimental biology, and steered me to Dr Martyn Caldwell at Utah State University. I was very nervous about moving to a new system in the western US, especially an arid system, but my advisor assured me that if you understand basic principles in ecology you can apply those to a new system, and to view this opportunity to study abroad as an adventure. This led me to seeing that there are great challenges and opportunities in studying around the world.

\section{Do you still find alpine systems alluring?}

I would love to work in an alpine setting, but at this point in time I have become so fond of the systems here in Central Mexico that my work is quite satisfying, especially working to help people sustain their lives and livelihoods on these landscapes. 
Where are your tool kit and the basic principles for studying social systems coming from?

These skills and principles are coming from colleagues and new collaborations. Much of this is a commonsense approach of listening to other people and coming to understand their perspectives. Working with social scientists has led to some of these principles and skills, or at least resulted in the outcomes of learning to listen to people and understand their situations. There is only so much time, and it is difficult to learn another field as well as maintaining my own skills in ecology. Fortunately, I work with people who have created wonderful frameworks that I can use for our research. One key example is the work of Jim Reynolds from Duke University and his Dryland Development Paradigm. This conceptual framework for coupled humanecological systems in arid to subhumid environments is very useful for structuring our work and understanding how to effect change.

With this newer perspective on the human dimensions in these landscapes are you now seeing these patterns in nature differently than you had in the past, from primarily a biophysical point of view?

Yes, even now I think back to Austria and realize that the patterns I had studied there were actually strongly shaped by how those human communities managed their resources. Now, here in North America, I am seeing how many social factors are contributing to, if not driving, landscape patterns, including degradation.

How can you measure some degree of success or accomplishment in your work?

Success in large part would come from being in a position where I have a more complete understanding of these human-ecological systems to be able to provide relevant recommendations. The ultimate goal is to have these human communities see themselves as sustainable for future generations, that this can be a vision for their future. We have to start by ceasing land degradation. Maybe this is an illusion or an unattainable goal. I do know that this is a step-by-step process, and one that starts with education. In the end, real success would be for these people to have options, more options than they currently have. People living in urban areas have options, and I would like to see rural communities have a set of options where they can be secure and creative in their lives.

How do you see yourself and your career in the years to come?

I am still keenly interested in the ecology and biodiversity of these landscapes. There is still a tremendous amount of work to be done.

\section{So, you've found a profession and a setting that provides you with tremendous options?}

Yes. Working in San Luis Potosi is a paradise for an ecologist. We have arid grasslands, semiarid and mesic forest systems, coastal tropical forests, different cultures and indigenous peoples, a wide array of human-ecological systems to study, learn from, and contribute to. Though there are some limits to what I can do in these environments as a nonnative Spanish speaker and a female, my students don't have those limits, and they will be in a position to have real impacts, that is an ultimate goal. They can come to see that they too live in a paradise.

Interview was by Susan R. McGuire, a pen name used by the author of this article. Her interviews with members of our profession are a regular contribution to Rangelands. All costs of publishing these interviews are sponsored by a research unit of the Agricultural Research Service, the in-house research agency of the US Department of Agriculture, whose rangeland scientists are a segment of our Society. 